\title{
Physiological and metabolic alterations induced by commercial neonicotinoid formulations in Daphnia magna
}

\section{Anna Farkas ( $\square$ farkas.anna@blki.hu )}

Balaton Limnological Research Institute, Eötvös Lóránd Research Network (ELKH) https://orcid.org/0000-0003-1377-5887

\section{Dávid Somogyvári}

Balaton Limnological Research Institute, Eötvös Lóránd Research Network (ELKH)

\section{Attila W. Kovács}

Balaton Limnological Research Institute, Eötvös Lóránd Research Network (ELKH)

\section{Mária Mörtl}

Agro-Environmental Research Institute, National Agricultural Research and Innovation Centre, Budapest András Székács

Agro-Environmental Research Institute, National Agricultural Research and Innovation Centre, Budapest János Győ́ri

Balaton Limnological Research Institute, Eötvös Lóránd Research Network (ELKH)

\section{Research Article}

Keywords: neonicotinoids, Daphnia magna, thoracic limb activity, heart rate, ECOD activity

Posted Date: October 5th, 2021

DOl: https://doi.org/10.21203/rs.3.rs-429401/v1

License: (c) (i) This work is licensed under a Creative Commons Attribution 4.0 International License. Read Full License

Version of Record: A version of this preprint was published at Ecotoxicology on January 28th, 2022. See the published version at https://doi.org/10.1007/s10646-022-02520-y. 
Physiological and metabolic alterations induced by commercial neonicotinoid formulations in Daphnia magna

Anna Farkas ${ }^{\mathrm{a},{ }^{*}}$, Dávid Somogyvária ${ }^{\mathrm{a}}$, Attila W. Kovács ${ }^{\mathrm{a}}$, Mária Mörtt ${ }^{\mathrm{b}}$, András Székács ${ }^{\mathrm{b}}$, János Győria $^{\mathrm{a}}$

aBalaton Limnological Research Institute, Eötvös Loránd Research Network (ELKH), Hungary

${ }^{\mathrm{b}}$ Agro-Environmental Research Centre, Institute of Environmental Sciences, Hungarian University of Agriculture and Life Sciences, Hungary

* Corresponding author. Tel.: +36 87448 244. E-mail address: farkas.anna@blki.hu (A. Farkas).

\section{Abstract}

Neonicotinoid insecticides are widely used agents in agriculture to control a broad range of insect pests. Although use of neonicotinoid pesticides has resulted in the widespread contamination of surface waters, sublethal toxicity data of these products in relation to nontarget aquatic biota are still poor. Therefore, the objective of this study was to assess the effects of two neonicotinoid pesticides with widespread use on the basic physiological functions: the thoracic limb activity and heart rate of Daphnia magna, and to screen for their potential to affect the cytochrome P450 monooxygenase system (ECOD activity) of daphnids. The considered pesticides were the acetamiprid- and thiacloprid based products Mospilan 20 SG and Calypso 480 SC, respectively. The dose-dependent variation in the three biological endpoints considered were assessed following $24 \mathrm{~h}$ exposures. The two neonicotinoid formulations elicited significant depression on the thoracic limb activity and heart rate of daphnids at doses close to the immobility thresholds of formulations ( $48 \mathrm{~h}-\mathrm{EC}_{50}$ : 
Mospilan $20 \mathrm{SG}=190 \mathrm{mg} \mathrm{L}^{-1}$; Calypso $480 \mathrm{SC}=120 \mathrm{mg} \mathrm{L}^{-1}$ ), an effect mainly attributable to the overall drop in the general health status of the organisms. The alterations in the physiological traits were significant at exposures to $190 \mathrm{mg} \mathrm{L}^{-1}$ for Mospilan $20 \mathrm{SG}$ and $48 \mathrm{mg}$ $\mathrm{L}^{-1}$ for Calypso $480 \mathrm{SC}$. The dose related variation in the ECOD activity of daphnids exposed to the selected neonicotinoid formulations followed a biphasic pattern, with starting effective doses for Mospilan 20 SG of $6.3 \mathrm{mg} \mathrm{L}^{-1}$ (= 1/20 of 48h-EC 50 for Daphnia neonates), and for Calypso $480 \mathrm{SC}$ of $0.034 \mathrm{mg} \mathrm{L}^{-1}\left(=1 / 4000\right.$ of $\left.48 \mathrm{~h}-\mathrm{EC}_{50}\right)$. Maximal ECOD activity $(2.2$ fold increase vs. controls) was induced by Mospilan 20 SG in daphnids exposed to $114 \mathrm{mg} \mathrm{L}^{-1}$ product $\left(=48 \mathrm{~h}-\mathrm{EC}_{20}\right)$, and by Calypso $480 \mathrm{SC}(1.8$ fold increase $)$ at $5.2 \mathrm{mg} \mathrm{L}^{-1}$ dose $(=1 / 20$ of 48h-EC 50 ). Our results outlined significant alterations in the physiological traits and ECOD activity in exposed daphnids at concentrations below the immobility thresholds (48h-EC 50 ) of the products used as benchmarks to rate their toxicity risks to aquatic biota. Therefore, we think our findings might deserve consideration in the environmental risk evaluation of these products.

Keywords: neonicotinoids; Daphnia magna; thoracic limb activity; heart rate; ECOD activity

\section{DECLARATIONS}

\section{Data availability}

The datasets generated during and/or analysed during the current study are available from the corresponding author on reasonable request.

\section{Animal Research (Ethics)}


All applicable international, national and institutional guidelines for the care and use of animals were followed.

\section{Consent to Participate (Ethics)}

Not applicable.

\section{Consent to Publish (Ethics)}

Not applicable.

\section{Plant Reproducibility}

Not applicable.

\section{Clinical Trials Registration}

Not applicable.

\section{Author Contribution}

Anna Farkas: Conceptualization, Methodology, Formal analysis, Investigation, Writing original draft. Dávid Somogyvári: Formal analysis, Investigation. Attila W. Kovács: Methodology, Formal analysis, Investigation, Writing - original draft. Mária Mörtl: Methodology, Formal analysis, Writing - original draft, Funding acquisition. András Székács: Resources, Writing - original draft. János Győri: Conceptualization, Funding acquisition, Writing - original draft. All authors commented on previous versions of the manuscript. All authors read and approved the final manuscript.

\section{Conflict of Interest}

We have no competing interests to declare 


\section{Funding}

This project was supported by the Hungarian Scientific Research Fund OTKA K-112712.

\section{Acknowledgement}

This project was supported by the Hungarian Scientific Research Fund OTKA K-112712.

The authors express their special thanks to Zsuzsa Fekete for her assistance in experimental work.

\section{Competing interests statement}

We have no competing interests to declare.

\section{Introduction}

Neonicotinoids are systemic insecticides widely used in crop production to control a broad range of insect pests (as reviewed by Morrisey et al., 2015). Owing to their high water solubility and proven persistence in soil and water, neonicotinoids became ubiquitous pollutants even in the aquatic environment, where they entered mainly through agricultural drainage (CCME, 2007; EFSA, 2008; Morrisey et al., 2015; Raby et al., 2018a). Neonicotinoids act on the nicotinic acetylcholine receptors in the central nervous system, through a mechanism highly conserved across many insect species, and similarly on other, non-target aquatic invertebrates (Zhang et al., 2000; Tomizawa and Casida, 2003, 2005; Vehovszky et al., 2015). Although most research has reported relatively lower toxicity of neonicotinoid insecticides to fish and crustaceans (Rico and Van den Brink, 2015), measurable toxicity to a range of other aquatic arthropods including insects (Dyptera, Trichoptera, Ephemeroptera) 
and some crustaceans (Amphipoda, Mysida, Podocopida) was demonstrated even at low environmentally relevant concentrations (Mineau and Palmer, 2013; Morrisey et al., 2015).

Within aquatic biota, cladocerans were proven to be quite tolerant to a range of neonicotinoids and their technical formulations (Jemec et al., 2007; Pavlaki et al., 2011; Raby et al., 2018a, 2018b), with most data reporting on more general endpoints as survival and reproduction success determined in both acute and chronic toxicity studies. However, to better understand the real risks of neonicotinoids to cladocerans, knowledge on their effects on the basic physiological functions of these organisms and on the efficiency to metabolize this class of xenobiotics are also essential. As earlier outlined by Ankley et al. (2010) mapping of linkages between impairments of physiological functions and alterations at cellular and molecular levels is essential to better understand the mechanisms of biological features of organisms in adverse outcome pathways (AOP). For example, in terrestrial insects it was already evidenced that differences in the sensitivity to neonicotinoids is primarily dependent on the differential affinity of neonicotinoids for the nicotinic acetylcholine receptor (nAChR) as the target site (Taillebois et al., 2014; Crossthwaite et al., 2017; Manjon et al., 2018). In addition, differential susceptibility of various insects to neonicotinoids was also found to strongly depend on the speed and efficiency to metabolize neonicotinoids by particular types of microsomal cytochrome P450 monooxygenases (CYP P450) (Sparks et al., 2013; Bass et al., 2015). We have hypothesized therefore, that even in the case of daphnids their low sensitivity to neonicotinoids is attributed not only to a low density- or lack in specific receptor configurations, but also the xenobiotic metabolizing system of the organism will affect the toxicity potential of neonicotinoid pesticides. 
To date, information on the effects of neonicotinoid insecticides on the basic physiological functions of daphnids are scarce. A single study by Bownik et al. (2017) reports alterations in the heart rate and thoracic limb activity of daphnids under acute exposure to an acetamiprid based formulation (Mospilan 20 SP). In the study by Bownik et al. (2017) impairments in the heart rate and thoracic limb activity of daphnids were assessed within the $25-100 \mathrm{mg} \mathrm{L}^{-1}$ concentration range, at concentrations approaching the $48 \mathrm{~h}-\mathrm{EC}_{50}$ toxicity threshold of the product (Daphnia magna $48 \mathrm{~h}-\mathrm{EC}_{50}>100 \mathrm{mg} \mathrm{L}^{-1}$, as per the OECD Guideline 202).

In ecotoxicity studies with Daphnia magna as indicator organisms, the thoracic limb activity and heart rate proved to be sensitive endpoints to rate the deleterious effects of toxicants (Paul et al., 1997; Lovern et al., 2007; Lari et al., 2017a; 2017b; Bownik, A., 2020). Lowered heart contraction frequency of $D$. magna (considered as a physiologic indicator of the metabolic rate of the organism) imply significant disturbances in the haemolymph and nutrient circulation throughout the body of daphnids (Gruithuisen, 1828 as cited by Steinkey et al., 2019). Thoracic limb activity determines both the feeding and respiration rate of daphnids (Smirnov 2013; Lari et al., 2017a), as the movement of thoracic limbs directs food particles to the food groove of the organism and, at the same time ensures a propulsion for gas exchange over the body surface of daphnids (Pirow et al., 1999a; 1999b, Lari et al., 2017a).

Based on knowledges mentioned above, the purposes of this study were first to investigate the potential of two commercial neonicotinoid formulations: Mospilan 20 SG (active ingredient (a.i.) acetamiprid), and Calypso 480 SC (a.i. thiacloprid) to alter the heart rate and thoracic limb activity of Daphnia magna following acute (24 hours) exposure. In addition to physiologic traits evaluation, we have assessed also the CYP P450 enzyme activity variation 
(as ECOD) in exposed daphnids as a cellular marker of xenobiotic metabolism. In this study we have intentionally tested the formulated products in order to address also the potential harm of additives present in the product. Previously, in acute bioassays with Daphnia magna (conform OECD Guideline 202) we have already demonstrated for Mospilan 20 SG a toxicity potential 1.3 and 19.6 times higher than that explained by its acetamiprid and linear alkylbenzene sulfonate content (Mörtl et al., 2019), while for Calypso 480 SC antagonism was evidenced, with the toxicity of the formulation $2-3$ times lower than that expected according its thiacloprid content (Takács et al., 2017). In addition, testing of pesticides not only as pure active compounds but also as commercial formulations is increasingly supported in order to avoid the misinterpretation of their toxicological profile (as reviewed by Nagy et al., 2020).

The two neonicotinoid formulations were selected owing their widespread use in both intensive crop production as well as in households as pest control agents resulting in increased incidences of active compound detections in surface waters. Globally, environmental concentrations of acetamiprid were reported in approximately $50 \%$ of water monitoring studies ranging from 0.008 to $44.1 \mu \mathrm{g} \mathrm{L}^{-1}$, with maximal concentrations as high as 225 mg L-1 (Anderson et al., 2013; Morrisey et al., 2015, Mörtl et al., 2020). In Australian rivers draining horticulture and vegetable cultivating regions, thiacloprid detections were evidenced in $27-93 \%$ of water samples, reaching concentrations up to $1.4 \mu \mathrm{g} \mathrm{L}^{-1}$ (SanchezBayo and Hyne, 2014).

Knowledge on the sublethal effects of these neonicotinoids in D. magna may contribute to a better judgement of the real environmental risks posed by their intensive use and help to 
develop safer water quality guidelines to protect aquatic biota from this unintended pollution pressure.

\section{Materials and methods}

\subsection{Agrochemical formulations and chemical analysis}

Experiments were performed with the neonicotinoid formulations Mospilan 20 SG (acetamiprid 20.2\%, Nippon SODA Co. Ltd., Japan), and Calypso 480 SC (thiacloprid $40.40 \%$, Bayer AG, Germany) purchased from local distributors. Stock solutions were freshly prepared for each exposure series by dissolving the commercial formulations in the media used for D. magna culturing. Exposure media were prepared from fresh stock solutions with nominal concentrations of $2000 \mathrm{mg} \mathrm{L}^{-1}$ for Mospilan $20 \mathrm{SG}$ and $1000 \mathrm{mg} \mathrm{L}^{-1}$ for Calypso 480 SC. The concentration of stock solutions was verified in each test series by means of the active ingredients (acetamiprid, thiacloprid) quantified in $1 \mathrm{ml}$ subsamples stored at $-22^{\circ} \mathrm{C}$ until chemical analysis. In addition, each test dilution was verified both at test initiation and end to verify the real concentrations of neonicotinoid exposure.

Acetamiprid and thiacloprid quantification was performed using a Younglin YL9100 ${ }^{\circ}$ HPLC system equipped with a YL9150 autosampler as previously described in Mörtl et al. (2016). Active ingredients were separated on a $\mathrm{C}_{18}$ column ( $150 \mathrm{~mm} \times 4.6 \mathrm{~mm}$ i.d., $5 \mu \mathrm{m}$ ) at $40{ }^{\circ} \mathrm{C}$. UV signals were recorded at $\lambda=252$ and $269 \mathrm{~nm}$. Eluent flow rate was $1.0 \mathrm{~mL} \mathrm{~min}^{-1}$ with isocratic elution for $10 \min (65: 35=A: B$ eluents, $A=90 \%$ water: $10 \% \mathrm{MeOH}, B=\mathrm{MeOH})$. Exposure media of control treatments did not contain any interfering matrix component therefore, the quantitation of active compounds was performed based on external calibrations with standard dilutions within the $0.050-120 \mathrm{mg} \mathrm{L}^{-1}$ concentration range. The limits of detection (LODs) for standards were 0.020 and $0.030 \mathrm{mg} \mathrm{L}^{-1}$ and the corresponding 
limits of quantification (LOQs) were 0.060 and $0.090 \mathrm{mg} \mathrm{L}^{-1}$ for acetamiprid and thiacloprid, respectively. For Calypso 480 SC exposures in the lowest dose, where the expected thiacloprid concentrations fell below LOQ, the active compound was extracted three times from $5 \mathrm{ml}$ of sample by using $100 \mu \mathrm{l}$ methanol and $2 \mathrm{ml}$ dichloromethane. The lower layers were combined, the organic phase was evaporated to dryness and the residue was resolved in $500 \mu \mathrm{l}$ of HPLC eluent used as mobile phase. Recoveries were determined in triplicates with spiked solutions containing $0.010 \mathrm{mg} \mathrm{L}^{-1}$ of thiacloprid. Average recovery was $93 \pm 4 \%$.

\subsection{Test organisms and exposure conditions}

Daphnia magna Straus were cultured at a density of 15 individuals $\mathrm{L}^{-1}$ in a mixture $(1: 1 \mathrm{v} / \mathrm{v})$ of reverse-osmosis water and a commercial spring water (Mizse, Hungary - conductivity 520 $\mu \mathrm{S} \mathrm{cm}{ }^{-1}$ at $\left.20^{\circ} \mathrm{C} ; \mathrm{pH}^{7} .6 ; 342 \mathrm{mg} \mathrm{L}^{-1} \mathrm{HCO}^{-} ; 62 \mathrm{mg} \mathrm{L}^{-1} \mathrm{Ca}^{2+} ; 23.9 \mathrm{mg} \mathrm{L}^{-1} \mathrm{Mg}^{2+}\right)$. During culturing the main quality parameters of the mixed media varied within the following ranges:

conductivity $280-330 \mu \mathrm{S}$ at $20^{\circ} \mathrm{C}$, hardness $80-84 \mathrm{mg} \mathrm{L}^{-1}$ as $\mathrm{CaCO}_{3}$, alkalinity $150-170 \mathrm{mg}$ $\mathrm{L}^{-1}$ as $\mathrm{CaCO}_{3}, \mathrm{pH}_{7.4}-8.2$, dissolved oxygen $7.4-7.8 \mathrm{mg} \mathrm{L}^{-1}$. D. magna were raised in a temperature-controlled room at $22 \pm 1^{\circ} \mathrm{C}$ and $16: 8$ hours light-dark photoperiod with white fluorescent lamps as a light source. The freshwater media was changed twice weekly and neonates were removed every $24 \mathrm{~h}$. Before renewal, the fresh media was aerated for two hours to ensure the appropriate oxygen saturation. D. magna cultures were fed daily with Raphidocelis subcapitata algae at a minimum concentration of $10^{5}$ cells $\mathrm{mL}^{-1}$ and additional supplementation of powdered commercially available fish food $\left(0.9-1.2 \mathrm{mg} \mathrm{L}^{-1}\right)$ formulated for juvenile tropical fish (Fix 1., distributor Aqua-Life Kft, Hungary). Semi-static R. subcapitata cultures were grown at $22{ }^{\circ} \mathrm{C}$ in BG11 medium (Ripka et al., 1979) without nitrate. 
Five-days-old daphnids were exposed for 24 hours to five serial dilutions of neonicotinoid formulations within the following concentration ranges: Mospilan $\left(0.63-190 \mathrm{mg} \mathrm{L}^{-1}\right)$, Calypso $\left(0,025-120 \mathrm{mg} \mathrm{L}^{-1}\right)$. Exposures were performed in 6 well plates (NUNC BioLite 6 well Multidish plate, Thermo Fisher Scientific, Rochester, NY) by incubating two daphnids in $10 \mathrm{ml}$ of exposure media. Each treatment was applied in duplicate in a test series, and the tests were repeated four times (resulting 16 replicates per treatment and per endpoint). Exposures were run similarly in a temperature-controlled room at $22 \pm 1^{\circ} \mathrm{C}$ and $16: 8$ hours light-dark photoperiod with white fluorescent lamps as a light source. Each test series contained two control wells with untreated daphnids, finally resulting in 16 control datasets for heartbeat and thoracic limb activity.

In general, equitoxic concentrations of the two pesticides were preselected for assays at dilutions of $1 / 4000-, 1 / 400-, 1 / 20-$ and $1 / 4$ of the $48 \mathrm{~h}-\mathrm{EC}_{50}-\mathrm{S}$, as well as the $48 \mathrm{~h}-\mathrm{EC}_{20}$ and $48 \mathrm{~h}-\mathrm{EC}_{50}$ thresholds of the formulations, which were previously determined for neonates in acute immobilization tests as per the OECD 202 Guideline (OECD202, 2004). According preliminary tests, some differences in the final exposure concentrations of pesticides was introduced to better outline the dose-dependent variations of targeted endpoints. Based on immobilization tests the 48h-EC20 and $\mathrm{EC}_{50}$ thresholds for Mospilan 20 SG were 114 (103131) and $186(\mathrm{Cl}: 171-214) \mathrm{mg} \mathrm{L}^{-1}$, while for Calypso 480 SC were $52(41-71)$ and 119 (108 - 130) $\mathrm{mg} \mathrm{L}^{-1}$ (as mean and $95 \%$ confidence limits (Cl); personal unpublished data). Finally, the nominal exposure concentrations varied for Mospilan 20 SG between $0.63-190 \mathrm{mg} \mathrm{L}^{-1}$ and for Calypso 480 SC between $0.034-120 \mathrm{mg} \mathrm{L}^{-1}$ ranges.

Within independent exposures, the concentration of formulations remained relatively constant, as revealed by active ingredient quantifications in old exposure media. The 
concentrations of neonicotinoid active compounds in control media were always lower than the limits of quantification (<LOQ). As mean measured concentrations of acetamiprid and thiacloprid in exposure media varied within $108 \pm 27 \%$ and $103 \pm 11 \%$ of the preselected nominal doses, the mean measured concentrations in old exposure media were used in data presentation and statistical analysis.

2.3. Video microscopy of the heartbeat and thoracic limb activity of $D$. magna

Following exposures, the thoracic limb activity and heartbeat of daphnids was recorded using a Leica M205C stereo microscope equipped with a Leica DFC450 camera (Leica Microsystems, Germany) at a $40 \mathrm{x}$ total magnification. Thirty-second video records with a frame rate of 100 frames per second were taken simultaneously for two daphnids transferred in $100 \mu$ media on a glass slide. Stabilization of daphnids during recording was assured by the surface tension of the media as previously established by Villegas-Navarro et al. (2003). The heartbeat and thoracic limb activity of control- and treated daphnids was evaluated by reviewing the video records in slow motion at $25 \%$ of normal speed, and visually counting the number of thoracic limb beats and heart contractions within 10 and 5 seconds time intervals arbitrarily selected in each record.

\subsection{In vivo cytochrome P450 (as ECOD) activity estimation}

The ECOD activity of daphnids exposed to neonicotinoid formulations was indirectly evaluated as per the methods of Gottardi et al. (2016) and adapted from Gagnaire et al., (2010). The assay principle is based on assessing in vivo the conversion of 7-ethoxycoumarin- 
O-deethylase (as the substrate) to 7-hydroxycoumarin by the cytochrome P450 enzymes of exposed daphnids. For this purpose, five-days-old daphnids ( 5 individuals per $20 \mathrm{ml}$ exposure media) were exposed for 24 hours at identical test concentrations as those used in the physiological traits assessment tests. Each treatment was applied in duplicate in a test series and the tests were repeated three times (resulting in 6 replicates per treatment). Following pre-exposure, daphnids were incubated in groups of five individuals in $2 \mathrm{ml}$ volumes of exposure media spiked with 7-ethoxycoumarin (0.01 mM final concentration) in 24 well plates (NUNC BioLite 6 well Multidish plate, Thermo Fisher Scientific, Rochester, NY). Incubation was performed in complete darkness for three hours at $22 \pm 1{ }^{\circ} \mathrm{C}$. Parallel subsamples of incubation media devoid of organisms served as blanks for determining the background fluorescence of the substrate. During incubation, $100 \mu \mathrm{L}$ aliquots of incubation media were transferred every 30 minutes into wells of a black microplate (OptiPlate 96F, PerkinElmer Inc., USA) for fluorescence recording using a microplate reader (VICTOR ${ }^{3}$ M 1420 Multilabel Counter, PerkinEImer Inc., USA). Fluorescence measurements were performed at room temperature, using the following fluorescence filter pairs: excitation $=355 \pm 40 \mathrm{~nm}$, emission $=460 \pm 25 \mathrm{~nm}$. Blank corrected fluorescence values recorded over time were then converted to total amount of 7-hydroxycoumarin by means of a calibration curve of 7hydroxycoumarin standard ( $0-50 \mathrm{pmol}$ range, in distilled water). Here, the progressive decrease in incubation volume was taken into consideration. ECOD activity was finally determined as the slope of a linear regression (Origin Pro 95E, OriginLab Co., USA) fitted in the linear range of the 7-hydroxycoumarin concentrations determined during the three hours incubation time. ECOD activity was expressed in pmol 7-hydroxycoumarin $\mathrm{h}^{-1}$ $\left.\operatorname{organism}^{-1}\right)$. 


\subsection{Statistical analysis}

Datasets were first subjected to an outlier analysis according to Chauvenet's criterion and extreme values excluded, resulting in final $\mathrm{n}$ data from 14 to 16 for physiological endpoints and 5 to 6 data for ECOD activity. Datasets were further tested for normality and homogeneity of variances by a Shapiro-Wilk and Levene's tests. Thoracic limb beat frequency- and heart rate datasets met the assumptions for parametric analysis thus, differences in physiological endpoint values observed within different treatment conditions were analysed for significance by one-way ANOVA $(p=0.05)$, followed by Tukey's means comparisons test.

For ECOD activity data the population variances were significantly different at $p \leq 0.05$ therefore, the significance of differences between the datasets of different treatments was assessed using a Kruskal-Wallis test and Mann-Whitney $U$ test. Statistical analyses and graphical plotting were performed in OriginPro (OriginPro 95E, OriginLab Co., USA).

\section{Results}

3.1. Physiological responses in D. magna exposed to neonicotinoid formulations

Control daphnids were characterised by a mean thoracic limb beating frequency of $233 \pm 28$ beats $\mathrm{min}^{-1}$ and a baseline heart rate of $403 \pm 29$ beats $\mathrm{min}^{-1}$. Compared to control treatments, both neonicotinoids elicited significant decrease in the thoracic limb activity of daphnids at concentrations equal-, or close to the $48 \mathrm{~h}-\mathrm{EC}_{50}$ thresholds of the formulations (Fig. 1). 
A

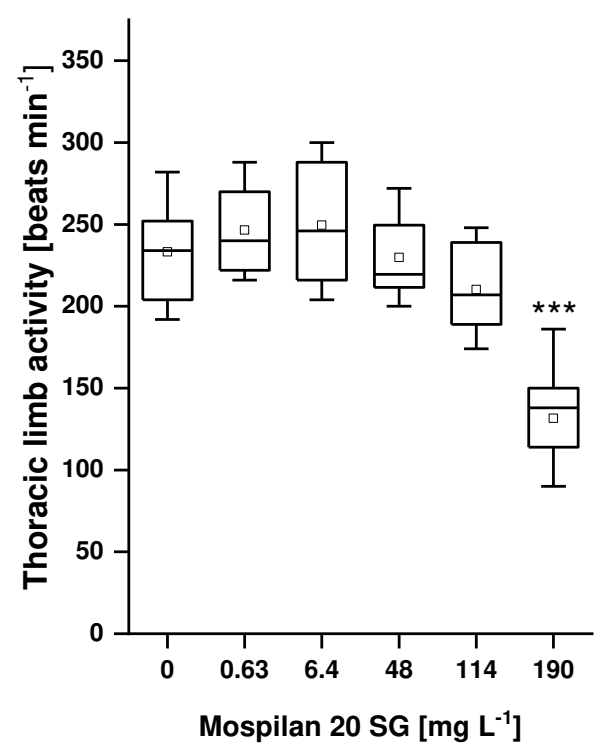

B

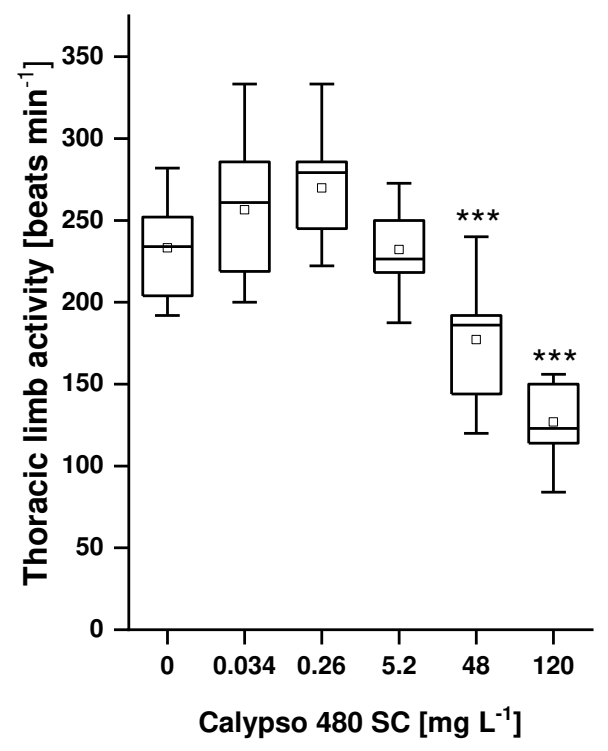

Fig.1. Thoracic limb activity in Daphnia magna following $24 \mathrm{~h}$ exposure to A: Mospilan 20 SG and B: Calypso 480 SC. Plots represent the median (square), $25-75 \%$ percentiles (box) and $10^{\text {th }}-90^{\text {th }}$ percentiles range (whiskers) values $(n=14-16$ individual recordings per treatment). Asterisks indicate significant differences $(* * * p<0.001)$ between data recorded in unexposed individuals and those exposed to formulations (ANOVA, Tukey test). For each datasets normality and homogeneity of variances were met (Shapiro-Wilk, Levene's test, $p<$ $0.05)$.

Mospilan 20 SG caused significant drop in the thoracic limb activity of daphnids at the 190 $\mathrm{mg} \mathrm{L}^{-1}$ dose (by $44 \%$ ) as compared to the control (Fig. $1 \mathrm{~A}: \mathrm{F}(5,93)=39.7 ; p<0.001$ ). In daphnids exposed to Calypso 480 SC statistically significant decrease in thoracic limb activity (by 24\%) was observed at the $48 \mathrm{mg} \mathrm{L}^{-1}$ exposure dose, which corresponds to the $48 \mathrm{~h}-\mathrm{EC}_{20}$ of the formulation, while in the highest dose applied $\left(120 \mathrm{mg} \mathrm{L}^{-1}\right)$ the thoracic limb activity decreased by $46 \%$ as compared to the control (Fig. $1 \mathrm{~B}: \mathrm{F}(5,92)=43.6 ; p<0.001$ ). For both 
formulations, low dose exposures elicited increases in thoracic limb activity of daphnids (by $7-16 \%)$ as compared to control; however, the differences were not statistically significant.

The pattern of alterations in the heart beating frequency of daphnids exposed to the formulations revealed a similar variation pattern to that observed for thoracic limb activity (Fig. 2 A,B).

A

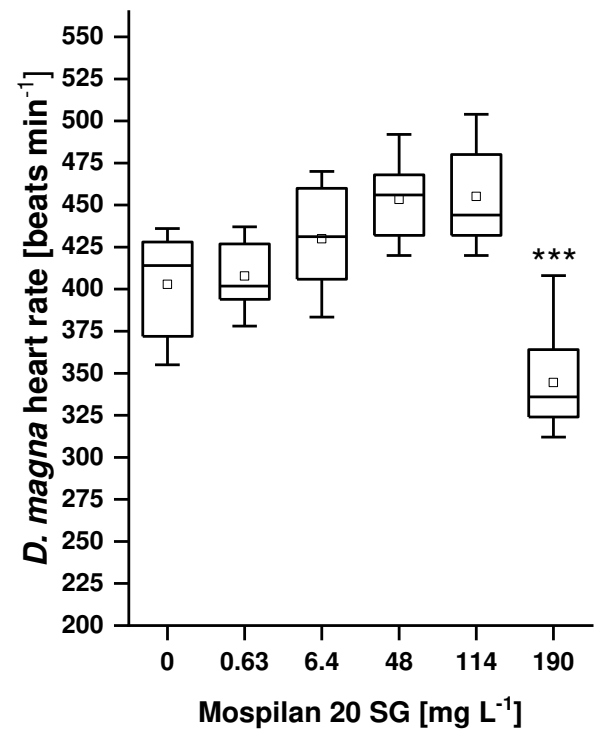

B

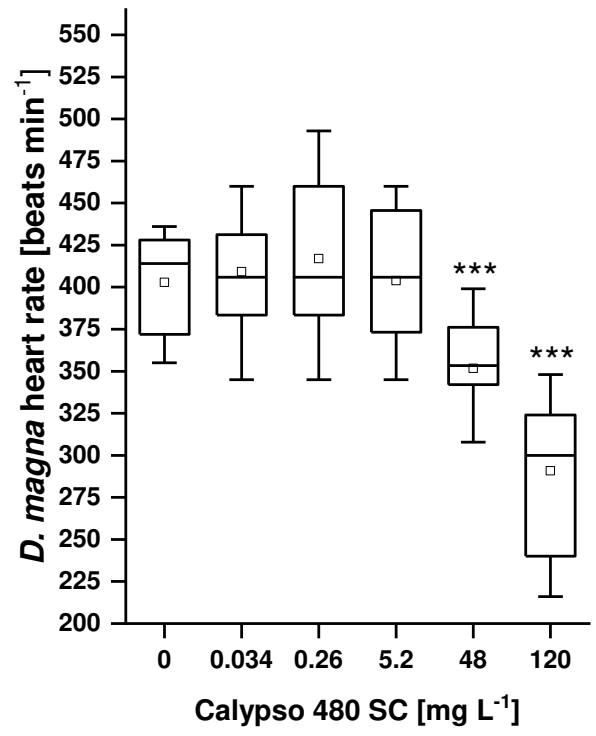

Fig.2. Heart rate in Daphnia magna following 24 h exposure to A: Mospilan 20 SG and B:

Calypso 480 SC. Plots represent the median (square), $25-75 \%$ percentiles (box) and $10^{\text {th }}-90^{\text {th }}$ percentiles range (whiskers) values ( $n=14-16$ individual recordings per treatment). Asterisks indicate significant differences $\left({ }^{* * *} p<0.001\right)$ between data recorded in unexposed individuals and those exposed to neonicotinoids (ANOVA, Tukey test). For each 
datasets normality and homogeneity of variances were met (Shapiro-Wilk, Levene's test, $p<$ $0.05)$.

In daphnids exposed to Mospilan 20 SG a progressive but statistically insignificant increase in heart rate (by maximum $13 \%$ ) was observable up to the $48 \mathrm{~h}-\mathrm{EC}_{20}$ threshold of the product (114 $\mathrm{mg} \mathrm{L}^{-1}$ ) compared to control then, a significant drop (by 14\%) in heart beating frequency was recorded at the highest $190 \mathrm{mg} \mathrm{L}^{-1}$ exposure concentration (Fig. $2 \mathrm{~A}: \mathrm{F}(5,87)=37.6$; $p<0.001$ ). For daphnids exposed to Calypso 480 SC statistically significant decrease in the heart beating frequency (by 13\%) relative to the control was observed at the $48 \mathrm{mg} \mathrm{L}^{-1}$ exposure dose (corresponding to the $48 \mathrm{~h}-\mathrm{EC}_{20}$ of the product) followed by further decline (by $28 \%$ ) upon exposure to $120 \mathrm{mg} \mathrm{L}^{-1}$ (Fig. 2B: $F(5,95)=29.08 ; p<0.001$ ). In the low dose range $\left(0.034-5.20 \mathrm{mg} \mathrm{L}^{-1}\right)$ Calypso $480 \mathrm{SC}$ had no apparent effect on the heart rate of daphnids.

3.2. Modulation of ECOD activity in D. magna exposed to neonicotinoid formulations

The mean ECOD activity of control daphnids was $1.26 \pm 0.10 \mathrm{pmol} \mathrm{h}^{-1}$ organism $^{-1}$, a baseline level which is comparable to data previously reported by Gottardi et al. $(2016$; 2019) for organisms of similar developmental stage. Exposure to both neonicotinoid pesticides elicited significant induction in the ECOD activity of daphnids compared to controls within the whole dose-range tested, with the enzyme activity displaying a biphasic pattern (Fig. 3). 
A

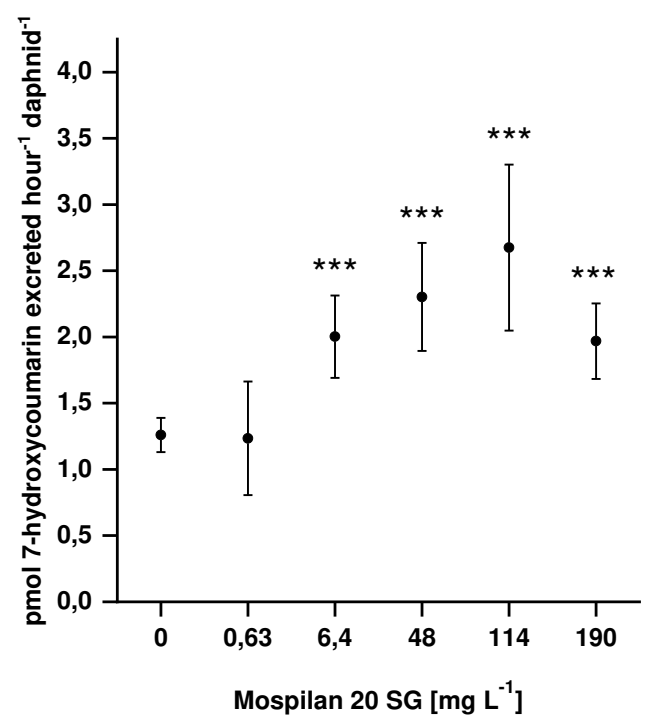

B

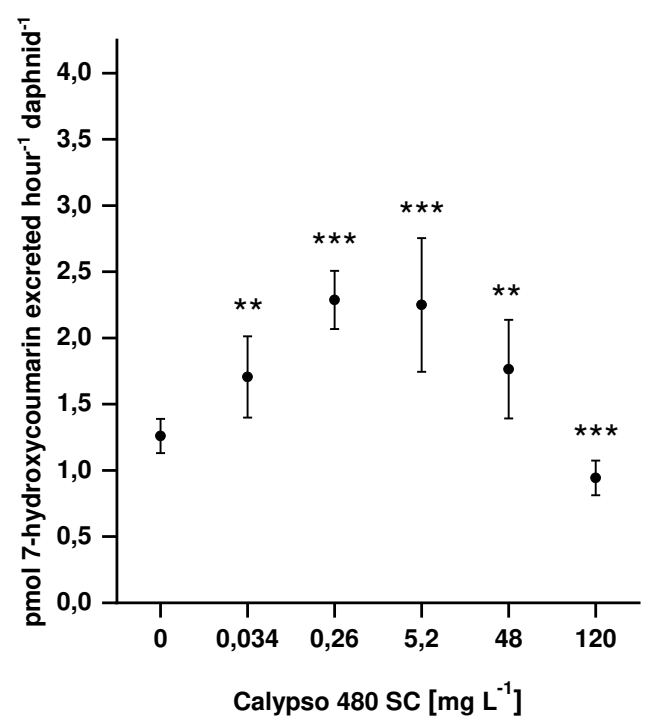

Fig. 3. (A) Effect of Mospilan 20 SG exposure (24h) on ECOD activity in five days old Daphnia magna. (B) Effect of Calypso 480 SC exposure (24h) on ECOD activity in five days old Daphnia magna. Data are presented as mean \pm SD for $5-6$ replicates per treatment. Exposure groups labelled by ${ }^{* *}$ and $* * *$ significantly differed from control datasets at $p<0.01$ and $p<0.001$ respectively (Mann-Whitney $U$ test).

Lowest effective concentrations causing significant induction in ECOD activity were of $6.4 \mathrm{mg}$ $\mathrm{L}^{-1}$ for Mospilan $20 \mathrm{SG}\left(1 / 20\right.$ of $\left.48 \mathrm{~h}-\mathrm{EC}_{50}\right)$ and of $0.034 \mathrm{mg} \mathrm{L}^{-1}$ for Calypso $480 \mathrm{SC}$ (1/4000 of 48h-EC 50 ). For Mospilan 20 SG, maximal 2.2 fold increase in ECOD activity compared to controls was detected at the $114 \mathrm{mg} \mathrm{L}^{-1}$ exposure dose (= 48h-EC 20 of the product), which was followed by a fall-off in enzyme activity (by $26 \%$ vs. the maximal ECOD activity level) upon exposure to the highest exposure dose of $190 \mathrm{mg} \mathrm{L}^{-1}$ product $\left(=48 \mathrm{~h}-\mathrm{EC}_{50}\right.$ ) (Fig. 3A; 
Mann-Whitney $U$ test, $p<0.001)$. In daphnids exposed to Calypso 480 SC maximal 1.8 fold increase in enzyme activity was measured at the $5.2 \mathrm{mg} \mathrm{L}^{-1}$ dose $\left(=1 / 20\right.$ of $\left.48 \mathrm{~h}-\mathrm{EC}_{50}\right)$. Further increase in treatment dose resulted in a progressive decrease in ECOD activity even significantly below the baseline level (by 25\%; Mann-Whitney U test, $p<0.001$ ) characteristic for untreated daphnids (Fig. 3B).

\section{Discussion}

The tested neonicotinoid formulations exerted significant alterations in the thoracic limb activity and the heart beating rate of five days old daphnids only in concentrations approaching the $D$. magna $48 \mathrm{~h}-\mathrm{EC}_{50}$ thresholds (Mospilan $20 \mathrm{SG}: 186(\mathrm{Cl}: 171-214) \mathrm{mg} \mathrm{L}^{-1}$; Calypso 480 SC: $\left.119(\mathrm{Cl}: 108-130) \mathrm{mg} \mathrm{L}^{-1}\right)$. At the highest doses applied, both neonicotinoids elicited closely similar reduction (by $44-$ and $46 \%$ respectively) in the beating frequency of the thoracic limbs. Such a drop in thoracic limb activity reduces both the overall food uptake and gas exchange by organisms, leading to reduced energy allocation, growth performance and reproduction, which finally may severely compromise the chances of survival of affected organisms (Friberg-Jensen et al., 2010; Lari et al., 2017b). Reduction in thoracic limb activity of daphnids was also reported in relation to high concentrations of particulate matter including food (Kirk, 1991; Peñalva-Arana et al., 2007; Lovern et al., 2007; Lari et al., 2017a) but also in response to dissolved toxicants as well (Friberg-Jensen et al., 2010; Lari et al., 2017a; Bownik and Stępniewska, 2015; Bownik et al., 2018; Bownik et al., 2019a; 2019b). A decrease in the thoracic limb activity of daphnids in the presence of high particulate matter densities is considered a natural response (Lari et al., 2017a), while in the case of dissolved substances the inhibition of this physiological feature is supposed to be 
linked to the depressive action of bioactive compounds on the $\mathrm{Na}^{+} / \mathrm{K}^{+}$ATP-ase activity resulting in a decreased transmission between neurons and muscles of the thoracic limbs (Bownik et al., 2019a).

The characteristic effects of the two neonicotinoid formulations on the heart beating frequency of daphnids was slight (but statistically insignificant) increase in the low dose exposures, followed by significant depression at doses close to the $48 \mathrm{~h}-\mathrm{EC}_{50}$ of the products. Early studies by Ermakov (1937 as cited by Smirnov, 2013) outlined that $\mathrm{Ca}^{2+}$ concentration plays a role in adjusting the heart rate of $D$. magna. Ingle et al. (1937 as cited by Steinkey et al., 2019) stated that an increase in the heart rate of Daphnia is most probably due to a downregulation in $\mathrm{Ca}^{2+}$ concentration, as an increase in $\mathrm{Ca}^{2+}$ concentration was proven to reduce the heart rate of daphnids through induction of diastolic arrest. Bekker and Krijgsmann (1951), in their investigation focused on mapping the mechanism of the heart in Daphnia, reported heart rate depression in daphnids exposed to nanomolar concentrations of acetylcholine or micromolar concentrations of tetraethylpyrosphosphate, a phenomenon presumed to be a specific toxic response of the myogenic pacemaker of the Daphnia heart. As significant alterations in thoracic limb activity and heart rate in exposed daphnids were detected at doses close to the immobility thresholds of the products, it is assumed that these responses are attributable to a significant drop in the general health status of organisms, rather than a specific toxic action of the products.

In contrast to the physiological responses, a significant dose-dependent alteration in the ECOD activity of daphnids exposed to the neonicotinoid formulations was detected at lower (much below $\mathrm{EC}_{50}$ thresholds) doses of pesticide formulations. Exposure of daphnids to the neonicotinoid formulations elicited significant dose-dependent induction in the ECOD 
activity of organisms, suggesting that the cytochrome P450 mediated metabolism in daphnids was activated. Effective concentrations that significantly induced the ECOD activity of daphnids were well below the acute toxicity thresholds of the products, which in terms of active ingredient contents corresponded to $1.3 \mathrm{mg} \mathrm{L}^{-1}$ acetamiprid and $0.014 \mathrm{mg} \mathrm{L}^{-1}$ thiacloprid. These data seem to have environmental relevance particularly for Calypso 480 SC because this effective dose already approaches thiacloprid detections of $0.02-4.50 \mu \mathrm{g}^{-1}$ reported in surface waters worldwide (Sanchez-Bayo and Hyne, 2014; Velisek and Stara, 2018). This presumption is further supported by Morrisey et al. (2015) who reported for individual neonicotinoid concentrations in surface waters a geometric mean of $0.13 \mu \mathrm{g} \mathrm{L}^{-1}$ and a geometric mean for peak concentrations of $0.63 \mu \mathrm{g} \mathrm{L}^{-1}$. Moreover, it was also outlined that these mean concentrations, computed from grab or spot samples, may underestimate by $50 \%$ the mean values (Xing et al., 2013) and mean peak loads by 1-3 orders of magnitude. Taking into consideration this last presumption, effective concentration thresholds that altered the ECOD activity in daphnids established in our study do not entirely exclude the possibility of toxic incidences caused by these commercial pesticides even under field conditions therefore, these data may have relevance even in relation to environmental risk assessment.

In daphnids, upregulation of certain cytochrome P450 genes were reported upon chronic exposure to acetaminophen (Kim et al., 2018) or to polystyrene nanoplastics (Wu et al., 2019). In addition, net inhibition toward cytochrome P450 activity (ECOD) by azole fungicides was demonstrated by Dalhoff et al., (2016). The results of our study demonstrate that the cytochrome P450 monooxygenase system of daphnids was significantly induced by the tested neonicotinoid formulations, and this metabolic pathway may contribute to the 
detoxification of the bioactive compounds present in the formulations, thus serving some protection against the toxicity of these pesticides.

\section{Conclusions}

The above data revealed that although sublethal concentrations of the acetamiprid-and thiacloprid based pesticides (Mospilan 20 SG and Calypso 480 SC, respectively) elicited only minor physiological alterations (decreased the thoracic limb beating frequency and heart rate), the biochemical compensatory mechanisms (activation of the cytochrome P450 monooxygenase system) started to respond from concentrations comparable to neonicotinoid concentrations already reported for surface waters. Our results therefore, suggest a relevant role for this metabolic pathway in the detoxification of the bioactive compounds present in formulations, moreover, support the concept to consider this biochemical marker (ECOD activity) to be used as a bioindication trait for environmental risk evaluation when neonicotinoid insecticides are concerned. 


\section{References}

Anderson, T.A., Salice, C.J., Erickson, R.A., McMurry, S.T., Cox, S.B., Smith, L.M., 2013. Effects of landuse and precipitation on pesticides and water quality in playa lakes of the southern high plains. Chemosphere 92, 84-90. https://doi.org/10.1016/j.chemosphere.2013.02.054 Ankley, G.T., Bennett, R.S., Erickson, R.J., Hoff, D.J., Hornung, M.W., Johnson, R.D., Mount, D.R., Nichols, J.W., Russom, C.L., Schmieder, P.K., Serrrano, J.A., Tietge, J.E., Villeneuve, D.L., 2010. Adverse outcome pathways: a conceptual framework to support ecotoxicology research and risk assessment. Environ Toxicol Chem 29, 730-741. https://doi.org/ 10.1002/etc.34

Bass, C., Denholm, I., Williamson, M.S., Nauen, R., 2015. The global status of insect resistance to neonicotinoid insecticides. Pestic Biochem Physiol 121, 78-87. https://doi.org/ 10.1016/j.pestbp.2015.04.004

Bekker, J.M., Krijgsman, B.J., 1951. Physiological investigations into the heart function of Daphnia. J Physiol 115, 249-257. https://doi.org/ 10.1113/jphysiol.1951.sp004669

Bownik, A., 2019a. Effects of ectoine on behavioral, physiological and biochemical parameters of Daphnia magna exposed to dimethyl sulfoxide. Sci Total Environ 683, 193201. https://doi.org/ 10.1016/j.scitotenv.2019.05.257

Bownik, A., 2020. Physiological endpoints in daphnid acute toxicity tests. Sci Total Environ 700, 134400. https://doi.org/ 10.1016/j.scitotenv.2019.134400 
Bownik, A., Kowalczyk, M., Banczerowski, J., 2019b. Lambda-cyhalothrin affects swimming activity and physiological responses of Daphnia magna. Chemosphere 216, 805-811. https://doi.org/ 10.1016/j.chemosphere.2018.10.192

Bownik, A., Pawłocik, M., Sokołowska, N., 2017. Effects of neonicotinoid insecticide acetamiprid on swimming velocity, heart rate and thoracic limb movement of Daphnia magna. Pol. J. Nat. Sci. 32, 481-493. ISSN:1643-9953

Bownik, A., Sokolowska, N., Slaska, B., 2018. Effects of apomorphine, a dopamine agonist, on Daphnia magna: Imaging of swimming track density as a novel tool in the assessment of swimming activity. Sci Total Environ 635, 249-258. https://doi.org/ 10.1016/j.scitotenv.2018.04.157

Bownik, A., Stepniewska, Z., 2015. Protective effects of ectoine on behavioral, physiological and biochemical parameters of Daphnia magna subjected to hydrogen peroxide. Comp Biochem Physiol C Toxicol Pharmacol 170, 38-49. https://doi.org/ 10.1016/j.cbpc.2015.02.002

CCME, 2007. Canadian Water Quality Guidelines: Imidacloprid, Scientific Supporting Document. Canadian Council of Ministers of the Environment, Winnipeg.

Crossthwaite, A.J., Bigot, A., Camblin, P., Goodchild, J., Lind, R.J., Slater, R., Maienfisch, P., 2017. The invertebrate pharmacology of insecticides acting at nicotinic acetylcholine receptors. J Pestic Sci 43(3), 67-83. https://doi.org/10.1584/jpestics.D17-019 
Dalhoff, K., Gottardi, M., Kretschmann, A., Cedergreen, N., 2016. What causes the difference in synergistic potentials of propiconazole and prochloraz toward pyrethroids in Daphnia magna? Aquat Toxicol 172, 95-102. http://dx.doi.org/10.1016/j.aquatox.2015.12.007

Ermakov, M.V., 1937. Nervous system and heart activity in invertebrates. II. On innervation of the heart in Cladocera. Medichnyi Zhurnal AN Ukr. SSR. 7, 263-275.

European Food Safety Authority (EFSA), 2008. Conclusion regarding the peer review of the pesticide risk assessment of the active substance imidacloprid. European Food Safety Authority Scientific Report. European Food Safety Authority.

Friberg-Jensen, U., Nachman, G., Christoffersen, K.S., 2010. Early signs of lethal effects in Daphnia magna (Branchiopoda, Cladocera) exposed to the insecticide cypermethrin and the fungicide azoxystrobin. Environ Toxicol Chem 29, 2371-2378. https://doi.org/ 10.1002/etc. 290

Gagnaire, B., Geffard, O., Noury, P., Garric, J., 2010. In vivo indirect measurement of cytochrome P450-associated activities in freshwater gastropod molluscs. Environ Toxicol 25, 545-553. https://doi.org/ 10.1002/tox.20515

Gottardi, M., Cedergreen, N., 2019. The synergistic potential of azole fungicides does not directly correlate to the inhibition of cytochrome P450 activity in aquatic invertebrates. Aquat Toxicol 207, 187-196. https://doi.org/ 10.1016/j.aquatox.2018.12.010

Gottardi, M., Kretschmann, A., Cedergreen, N., 2016. Measuring cytochrome P450 activity in aquatic invertebrates: a critical evaluation of in vitro and in vivo methods. Ecotoxicology 25, 419-430. https://doi.org/ 10.1007/s10646-015-1600-z 
Goulson, D., 2013. REVIEW: An overview of the environmental risks posed by neonicotinoid insecticides. J Appl Eco 50, 977-987. https://doi.org/ 10.1111/1365-2664.12111

Gruithuisen, F.V.P., 1828. Über die Daphnia sima und ihrer Blutkreislauf. Verhandlungen der Keiserlichen Leopoldinisch-Carolinischen Akademie der Naturforscher 6 (Nova acta physicomedica Academiae Cesareae Leopoldino-Carolinae naturae curiosorum, vol. 14, pp. 399-406. Ingle, I., Wood, T.R., Banta, A.M., 1937. A study of longevity, growth, reproduction and heart rate in Daphnia longispina as influenced by limitations in quantity of food. J Exp Zool 76, 325352. https://doi.org/10.1002/jez.1400760206

Jemec, A., Tisler, T., Drobne, D., Sepcic, K., Fournier, D., Trebse, P., 2007. Comparative toxicity of imidacloprid, of its commercial liquid formulation and of diazinon to a non-target arthropod, the microcrustacean Daphnia magna. Chemosphere 68, 1408-1418. https://doi.org/ 10.1016/j.chemosphere.2007.04.015

Kim, R.-O., M.-A., Song, J., Kim, I.-C., Yoon, S., Kim, W.-K; 2018. Novel approach of evaluating pharmaceuticals toxicity using Daphnia model: analysis of the mode of cytochrome P450generated metabolite action after acetaminophen exposure. Aquat Toxicol 196, 35-42. https://doi.org/10.1016/j.aquatox.2017.12.017

Kim, Y., Choi, K., Jung, J., Park, S., Kim, P.-G., Park, J., 2007. Aquatic toxicity of acetaminophen, carbamazepine, cimetidine, diltiazem and six major sulfonamides, and their potential ecological risks in Korea. Environ. Int. 33, 370-375.

htps://doi.org/10.1016/J.ENVINT.2006.11.017 
Kirk, K.L., 1991. Suspended Clay Reduces Daphnia Feeding Rate - Behavioral Mechanisms. Freshwater Biol 25, 357-365. https://doi.org/ DOI 10.1111/j.1365-2427.1991.tb00498.x

Lari, E., Steinkey, D., Morandi, G., Rasmussen, J.B., Giesy, J.P., Pyle, G.G., 2017a. Oil sands process-affected water impairs feeding by Daphnia magna. Chemosphere $175,465-472$. https://doi.org/ 10.1016/j.chemosphere.2017.02.088

Lari, E., Steinkey, D., Pyle, G.G., 2017b. A novel apparatus for evaluating contaminant effects on feeding activity and heart rate in Daphnia spp. Ecotoxicol Environ Saf 135, 381-386. https://doi.org/ 10.1016/j.ecoenv.2016.10.018

Lovern, S.B., Strickler, J.R., Klaper, R., 2007. Behavioral and physiological changes in Daphnia magna when exposed to nanoparticle suspensions (titanium dioxide, nano-C60, and C60HxC70Hx). Environ Sci Technol 41, 4465-4470. https://doi.org/ 10.1021/es062146p Manjon, C., Troczka, B.J., Zaworra, M., Beadle, K., Randall, E., Hertlein, G., Singh, K.S., Zimmer, C.T., Homem, R.A., Lueke, B., Reid, R., Kor, L., Kohler, M., Benting, J., Williamson, M.S., Davies, T.G.E., Field, L.M., Bass, C., Nauen, R., 2018. Unravelling the Molecular Determinants of Bee Sensitivity to Neonicotinoid Insecticides. Curr Biol 28, 1137-1143 e1135. https://doi.org/ 10.1016/j.cub.2018.02.045

Mineau, P., Palmer, C., 2013. Neonicotinoid insecticides and birds: the impact of the nation's most widely used insecticides on birds. American Bird Conservancy.

Morrissey, C.A., Mineau, P., Devries, J.H., Sanchez-Bayo, F., Liess, M., Cavallaro, M.C., Liber, K., 2015. Neonicotinoid contamination of global surface waters and associated risk to 
aquatic invertebrates: a review. Environ Int 74, 291-303. https://doi.org/

10.1016/j.envint.2014.10.024

Mörtl, M., Kereki, O., Darvas, B., Klátyik, S., Vehovszky, Á., Győri, J., Székacs, A., 2016. Study on Soil Mobility of Two Neonicotinoid Insecticides. Journal of Chemistry. https://doi.org/ Artn 4546584 10.1155/2016/4546584

Mörtl, M., Takács, E., Klátyik, Sz., Székács, A., 2019. Aquatic toxicity and loss of linear alkylbenzenesulfonates alone and in a neonicotinoid insecticide formulation in surface water. Sci Total Environ 652, 780-787. https://doi.org/10.1016/j.scitotenv.2018.10.211 Mörtl, M., Vehovszky, Á., Klátyik, Sz., Takács, E., Győri, J., Székács, A., 2020. Neonicotinoids: Spreading, Translocation and Aquatic Toxicity. Int J Environ Res Public Health 17, 2006. https://doi.org/10.3390/ijerph17062006

Nagy, K., Duca, R.C., Lovas, Sz., Creta, M., Scheepers, P.T.J., Godderis, L., Ádám, B., 2020. Systematic review of comparative studies assessing the toxicity of pesticide active ingredients and their product formulations. Environ. Res., 181 (2020), p. 108926. https://doi.org/10.1016/j.envres.2019.108926

OECD202, 2004. Daphnia sp. Acute Immobilisation Test, OECD Guideline for the Testing of Chemicals, Guideline 202

Paul, R.J., Colmorgen, M., Huller, S., Tyroller, F., Zinkler, D., 1997. Circulation and respiratory control in millimetre-sized animals (Daphnia magna, Folsomia candida) studied by optical methods. J Comp Physiol B 167, 399-408. https://doi.org/ DOI 10.1007/s003600050089 
Pavlaki, M.D., Pereira, R., Loureiro, S., Soares, A.M.V.M., 2011. Effects of binary mixtures on the life traits of Daphnia magna. Ecotox Environ Safe 74, 99-110. https://doi.org/ 10.1016/j.ecoenv.2010.07.010

Peñalva-Arana, D.C., Moore, P.A., Feinberg, B.A., DeWall, J., Strickler, J.R., 2007. Studying Daphnia feeding behavior as a black box: A novel electrochemical approach. Hydrobiologia 594, 153-163. https://doi.org/ 10.1007/s10750-007-9080-7

Pirow, R., Wollinger, F., Paul, R.J., 1999a. The importance of the feeding current for oxygen uptake in the water flea Daphnia magna. J Exp Biol 202, 553-562. https://doi.org/

Pirow, R., Wollinger, F., Paul, R.J., 1999b. The sites of respiratory gas exchange in the planktonic crustacean Daphnia magna: An in vivo study employing blood haemoglobin as an internal oxygen probe. J Exp Biol 202, 3089-3099. https://doi.org/

Raby, M., Nowierski, M., Perlov, D., Zhao, X.M., Hao, C.Y., Poirier, D.G., Sibley, P.K., 2018a. Acute Toxicity of 6 Neonicotinoid Insecticides to Freshwater Invertebrates. Environ Toxicol Chem 37, 1430-1445. https://doi.org/ 10.1002/etc.4088

Raby, M., Zhao, X.M., Hao, C.Y., Poirier, D.G., Sibley, P.K., 2018b. Relative chronic sensitivity of neonicotinoid insecticides to Ceriodaphnia dubia and Daphnia magna. Ecotox Environ Safe 163, 238-244. https://doi.org/ 10.1016/j.ecoenv.2018.07.086

Rico, A., Van den Brink, P.J., 2015. Evaluating aquatic invertebrate vulnerability to insecticides based on intrinsic sensitivity, biological traits, and toxic mode of action. Environ. Toxicol. Chem. 34, 1907-1917. https://doi.org/10.1002/etc.3008 
Rippka, R., Deruelles, J., Waterbury, J.B., Herdman, M., Stanier, R.Y., 1979. Generic Assignments, Strain Histories and Properties of Pure Cultures of Cyanobacteria. Journal of General Microbiology 111, 1-61. https://doi.org/ 10.1099/00221287-111-1-1

Sánchez-Bayo, F., Hyne, R.V., 2014. Detection and analysis of neonicotinoids in river waters Development of a passive sampler for three used insecticides. Chemosphere 99, 143-151. https://doi.org/10.1016/j.chemosphere.2013.10.051

Smirnov, N., 2013. Physiology of the Cladocea. Academic Press, San Diego, CA, USA.

Sparks, T.C., Watson, G.B., Loso, M.R., Geng, C.X., Babcock, J.M., Thomas, J.D., 2013.

Sulfoxaflor and the sulfoximine insecticides: Chemistry, mode of action and basis for efficacy on resistant insects. Pestic Biochem Phys 107, 1-7. https://doi.org/

10.1016/j.pestbp.2013.05.014

Steinkey, D., Lari, E., Woodman, S.G., Steinkey, R., Luong, K.H., Wong, C.S., Pyle, G.G., 2019. The effects of diltiazem on growth, reproduction, energy reserves, and calcium-dependent physiology in Daphnia magna. Chemosphere 232, 424-429. https://doi.org/ 10.1016/j.chemosphere.2019.05.176

Taillebois, E., Beloula, A., Quinchard, S., Jaubert-Possamai, S., Daguin, A. et al., 2014. Neonicotinoid Binding, Toxicity and Expression of Nicotinic Acetylcholine Receptor Subunits in the Aphid Acyrthosiphon pisum. PLoS ONE 9(5): e96669.

https://doi.org/10.1371/journal.pone.0096669

Takács, E., Klátyik, Sz., Mörtl, M., Rácz, G., Kovács, K., Darvas B., Székács A., 2017. Effects of neonicotinoid insecticide formulations and their components on Daphnia magna - the role 
of active ingredients and co-formulants. Int J Environ Anal Chem 97, 885-900.

http://dx.doi.org/10.1080/03067319.2017.1363196

Tomizawa, M., Casida, J.E. 2003. Selective toxicity of neonicotinoids attributable to specificity of insect and mammalian nicotinic receptors Annu Rev Entomol 48,339-364 https://doi.org/10.1146/annurev.ento.48.091801.112731

Tomizawa, M., Casida, J.E. 2005. Neonicotinoid insecticide toxicology: mechanisms of selective action. Annu Rev Pharmacol Toxicol 45, 247-268.

https://doi.org/10.1146/annurev.pharmtox.45.120403.095930

Vehovszky Á., Farkas A., Ács A., Stoliar O., Székács A., Mörtl M., Győri J., 2015. Neonicotinoid insecticides inhibit cholinergic neurotransmission in a molluscan (Lymnaea stagnalis) nervous system Aquatic Toxicology 167, 172-179.

https://doi.org/10.1016/j.aquatox.2015.08.009

Velisek, J., Stara, A., 2018. Effect of thiacloprid on early life stages of common carp (Cyprinus carpio). Chemosphere 194, 481-487. https://doi.org/10.1016/j.chemosphere.2017.11.176

Villegas-Navarro, A., Rosas-L, E., Reyes, J.L., 2003. The heart of Daphnia magna: effects of four cardioactive drugs. Comp Biochem Phys C 136, 127-134. https://doi.org/ $10.1016 / \mathrm{S} 1532-0456(03) 00172-8$

Wu, D., Liu, Z., Cai, M., Jiao, Y., Li, Y., Chen, Q., Zhao, Y., 2019. Molecular characterisation of cytochrome P450 enzymes in waterflea (Daphnia pulex) and their expression regulation by polystyrene nanoplastics. Aquat Toxicol 217, 105350. https://doi.org/ 10.1016/j.aquatox.2019.105350 
Xing, Z., Chow, L., Rees, H., Meng, F., Li, S., Ernst, B., Benoy, G., Zha, T., Hewitt, L.M., 2013. Influences of sampling methodologies on pesticide-residue detection in stream water. Arch Environ Contam Toxicol 64, 208-218. https://doi.org/ 10.1007/s00244-012-9833-9

Zhang, A., Kayser, H., Maienfisch, P., Casida, J.E., 2000. Insect nicotinic acetylcholine receptor: conserved neonicotinoid specificity of $[(3) \mathrm{H}]$ imidacloprid binding site. J Neurochem 75, 1294-1303. https://doi.org/ 10.1046/j.1471-4159.2000.751294.x 


\section{Supplementary Files}

This is a list of supplementary files associated with this preprint. Click to download.

- FarkasetalFig2.opju

- FarkasetalFig3.opju

- FarkasetalFig1.opju 